\title{
BECOMING A MOTHER: THE TRANSITION TO MOTHERHOOD IN CHIMAMANDA NGOZI ADICHIE'S ZIKORA
}

\author{
Miftahur Roifah \\ Universitas Trunojoyo Madura \\ e-mail: Miftahur.roifah@trunojoyo.ac.id
}

\begin{abstract}
In patriarchal society, motherhood is viewed as a responsibility for women although not all are willing or able to carry it on. To become a mother, a woman has to experience a challenging phase in life and ready to sacrifice everything they have. Feminist critics see motherhood as a complex issue operating patriarchal institution that regulates, dominates, and oppresses women. What is more, some women are not ready with the consequences during the transition to motherhood and bear the status of becoming a mother that often results in having a hard time. To bring this issue into discussion, this study is going to explore the crises that Zikora has to undergo in her transition to become a mother. Zikora is the protagonist in Chimamanda Ngozi Adichie's short story, Zikora. In analyzing the issue, this study applies the theory of motherhood by Andrienne Rich and uses a qualitative approach with a close reading method. The result of the study shows that motherhood brings women to a new world full of challenges. Motherhood requires not only physical strenght but also mental strenght and self control so that whatever the crises are, women can bear them and overcome the obstacles they are facing.
\end{abstract}

Keywords: motherhood, feminism, women, Zikora. 


\section{INTRODUCTION}

Literature often captures the struggle of women in doing their role as a mother. The topic of motherhood has been the focus of many writers in many fictional works. Throughout history, the struggle of women as a mother is more frequently portrayed as dramatic and problematic. It reflects the social realities of women's condition in dealing with motherhood. For some reasons, the topic of motherhood brought in literature is aimed to demonstrate the voice of women as motherhood is viewed as a socially constructed responsibility only for women (Tanjim, 2016). Therefore, many protagonists who bear the status of becoming a mother are depicted unhappy, angry, and depressed. Those protagonists who struggle with motherhood are commonly described from patriarchal society where men are excluded from this obligation (Alazaz, 2016) and often have less participation in parenthood.

Women and motherhood are complex issues which both of them are often being discussed by feminist scholars. Being pregnant is natural for a woman, but motherhood does not always come along with it. However, society always expects a woman who becomes a mother must be ready to perform the duty of motherhood. The idea of becoming a mother and the concrete demands of mothering are intertwined in an elusive convergence of biology, culture, and politics (Carlshamre, 2017). Motherhood is, thus, primarily not a natural or biological function, rather it is specifically and fundamentally a cultural practice (Hallstein, Reilly, \& Giles, 2020).

Among the narratives focusing on motherhood issues, Zikora is one of the newest. It is a short story written by a famous Nigerian Novelist, Chimamanda Ngozi Adichie. Not only about motherhood, Zikora also talks about womanhood, about love, hurts, women's strenght and weakness. According to (Osigwe \& Nekede, 2021), Zikora vividly explores some of the experiences women go through in becoming mothers. These experiences range from the complexity of romantic relationships, sexuality, childcare, physical and psychological changes and adjustment to motherhood, and social and cultural transitions. Moreover, Zikora is abandoned by her partner since he does not want to have a baby. As she has to experience pregnancy alone, with no support from her partner, her life is terrifying ordeal. She does not enjoy and get happiness in her transition to motherhood. She suffers from her early pregnancy untill she delivers the baby. Through the story of Zikora, Adichie wants to show various complexities in the life of a woman who is not ready and not willing to become a mother.

Since the theme of motherhood is still a contested issue in feminist research, this article is going to discuss how motherhood is experienced by Zikora in Zikora short story by Chimamanda Ngozi Adichie. To be specific, this article will explore the crisis Zikora has to undergo in her transition to motherhood. The crisis that will be discussed here is more into the challenges and changes that Zikora has. It also connects with the dilemma and psychological burden of becoming a mother when a woman has to experience motherhood with no man supports her. Since motherhood does not come along naturally with pregnancy, the analysis of this article will also look at how Zikora learns to become a mother and cope with the condition. The analysis of this article is seen through the perspective of motherhood by Andrienne Rich and other supported references.

Zikora is a new work which was published in 2020 and there has not been any study that analyze it. Most of the references for this short story are from book review. However, as the topic of the anaylsis in this article is about motherhood, there are myriads previous studies of it. As the context of Zikora's story is about African 
woman, one of the previous studies that in line with this article's discussion is the writing of Joyce Meier about The Refusal of Motherhood in African American Women's Theater (Meier, 2000). The article talks about the heroines in some plays who refuse motherhood and/ or child rearing because they cannot bear the alternative of birthing and raising a child in a culture that discriminates on the basis on race, culture, and gender. Moreover, another previous studies which has the same context with the issue brought in this article which is about the transition to motherhood is the writing of Katarina Carlshamre. She writes about Living the Paradox: The Transition to Motherhood in Two European Novels, the French A Happy Event and the Swedish Bitter Bitch (Carlshamre, 2017). The article mostly discusses about the dilemma of becoming a mother within the context of Western thought. This article will also uses some other previous studies and references which have connection in supporting the analysis.

\section{METHOD}

The method of this study is qualitative as it deals with texts in explaining and interpreting the data. In analyzing the transition to motherhood, this article explores short story, Zikora, written by Chimamanda Ngozi Adichie. The short story is taken as source of data because Adichie presents woman protagonist who struggles due to the her crisis in becoming a mother . To support the analysis, the study uses theory of motherhood in association with feminist criticism. The data is collected by reading character's utterances and writer's narration which involve the issues / the discussion about motherhood. The data then are classified and picked based on some points of analysis to further being interpreted and analyzed with the theory provided. Some references are also used to assist the analysis.

\section{Theoretical Framework}

The study of motherhood can be divided into four interconnected themes: the institution of motherhood, motherhood as experience, maternal identity or subjectivity, and finally maternal agency/activism. Within motherhood studies, the term motherhood is used to signify the patriarchal institution of motherhood, while the term mothering refers to women's lived experiences of childrearing as they both confirm to and/or resist the patriarchal institution of motherhood and its oppressive ideology (Hallstein et al., 2020).

Adrienne Rich's in her conceptual theory differenciates between motherhood and mothering which is principally organized by two standpoints: motherhood as institution and ideology, and mothering as experience and identity. The term "motherhood" refers to the patriarchal institution of motherhood, which is maledefined and controlled and is deeply oppressive to women, whereas the word "mothering" refers to women's experiences of mothering and is female-defined and centred and potentially empowering to women. In other words, whereas motherhood operates as a patriarchal institution to constrain, regulate, and dominate women and their mothering, mothers' own experiences of mothering can, nonetheless, be a site of empowerment (Hallstein et al., 2020).

Motherhood is, thus, primarily not a natural or biological function; rather, it is specifically and fundamentally a cultural practice that is continuously redesigned in response to changing economic and societal factors. As a cultural construction, its meaning varies with time and place; there is no essential or universal experience of 
motherhood. Patriarchal motherhood is neither natural nor inevitable. And since the patriarchal institution is socially constructed, it can be challenged and changed (Hallstein et al., 2020).

Motherhood is earned, first through an intense physical and psychic rite Of Passage" pregnancy and childbirth — then through learning to nurture, which does not come by instinct. After experiencing such process, women's body has undergone irreversible changes, her mind will never be the same, her future as woman has been shaped by the event. Under patriarchy, female possibility has been literally massacred on the site of motherhood. Most women in history have become mothers without choice, and an even greater number have lost their lives bringing life into the world (Rich, 1995).

Rich (Rich, 1995) also states that to have borned and reared a child is to have done that thing which patriarchy joins with physiology to render into the definition of femaleness. But also, it can mean the experiencing of one's own body and emotions in a powerful way. We experience not only physical, fleshly changes but the feeling of a change in character. Women did not simply give birth; She made it possible for the Chlld to go on living. Her breasts fumished the first food, but her concern for the child led her beyond that one-to-one relationship. The woman's body, with its potential for gestating, bringing forth and nourishing new life, has been through the ages a field of contradictions: a space invested with power, and an acute vulnerability; a numinous figure and the incarnation of evil; a hoard of ambivalences, most of which have worked to disqualify women from the collective act of defining culture. This matrix of life has been fundamental to the earliest division of labor (Rich, 1995).

\section{DISCUSSION}

Zikora's pregnancy is unexpected. When she realizes that she is late, she confesses to Kwame, her partner, that she may be pregnant. Knowing this fact, Kwame is shock because he assumes that they have safe sex. He said "I thought you let me because you had protection (Adichie, 2020)." Zikora replied "You know I stopped taking the pill because it made me fat, and I assumed you knew what it meant, what it could mean (Adichie, 2020)." Women do not have autonomy on her own body including to determine to be pregnant or not. Men are the one who decide and control the time. Taking pills to avoid pregnancy can actually put a woman's body at risk. Rich (Rich, 1995) in her writing mentions that the pill was believed by some, would release women from fear of pregnancy. However, by taking pill, women are expected to behave according to male notions of female sexuality and the pill itself is a mechanistic and patriarchal device, recently proven to have deadly side-effects (Rich, 1995). The use of pills signifies that to have a child for some couples is a burden, and thus so many of them try to avoid it.

Kwame sticks to his decision that he does not want the child so he abandons Zikora. "I think I should leave. Is that okay?" he asked as though he needed my permission to abandon me (Adichie, 2020)." Kwame's leaving is the beginning of all the crises that Zikora experiences in her transition to become a mother. His absence causes sadness, depression, and everyday is like a nightmare for her since she has to encounter problems during her pregnancy herself. She blames herself for her decision to stop the pills. "It has to be my birth control pills causing this, "I said, and there was again that small hesitation from him, a restraint, from discomfort rather than deceit. I could have been clearer when I stopped the pill, we could have talked plainly, as we talked about so much. Did I choose to assume he understood, because I didn't want to 
give him the chance to say he didn't want a child? Now I was blaming myself (Adichie, 2020)." In the process of becoming a mother, women experienced a sense of self-loss (Laney, Hall, Anderson, \& Willingham, 2015). At this stage, Zikora finds it difficult to accept the fact that she is pregnant and abondoned by her partner because he does not want the child. She is confused by the situation.

According to Rich (Rich, 1995) The unmarried mother has borne the most savage excoriations of church and society, and still carries a heavy burden of economic and social pressures which penalize her for her choice. Zikora also gets social pressures as she suffers from paranoia of what people thought about her "I cared now what people thought, and I had never cared before (Adichie, 2020)." Therefore, she tries to keep her struggle and do not let people know how hard her life is. "I just want them to know I can handle it, I can do it alone (Adichie, 2020)." For women, the transition to motherhood develops into an identity crisis. Their newfound situations challenge their ideas of who and what they are, and they have serious difficulties handling the emotional and practical chaos they fall into (Carlshamre, 2017).

Although women experience self-loss in their transition to become a mother and develop into an identity crisis, without them knowing it, at the same time they are developing motherhood identity. Some women experienced an epiphany of motherhood when they became deeply aware of having already become a mother (Laney et al., 2015). "Some days I was fine and some days I was underwater, barely breathing. At my twenty-week check up, I smiled at the moving grainy image on the ultrasound screen, flush with well-being, and I waved at the front-desk women as I left, but in the elevator, I burst into tears, a sudden sense of dissolving all around me (Adichie, 2020)." This scene shows that besides of her sadness going through pregnancy with no support of her partner, Zikora starts to feel the existence of the baby. She begins to pay attention to everything she does whether it harms the baby or not, such as the food she eats or the medicine she takes. "The pregnancy website said no soft cheese, and I stopped eating all cheese. They said don't take any medicine for nausea, and so I sucked natural ginger sweets (Adichie, 2020)." It can be said that in this stage, Zikora develops her motherhood nature, she learns to give attention and be more responsible to the baby.

Zikora experiences ups and downs in her transition to motherhood. Her feeling fluctuates from accepting and rejecting the reality she is facing. During her pregnancy she lives with full of struggle and when she is about to deliver the baby, she also has to go through difficult time. "I had prepared for pain but this was not mere pain. It was something like pain and different from pain. It sat like fire in my back, spreading to my thighs, squeezing and crushing my insides, pulling downward, spiraling (Adichie, 2020)." Childbirth is painful, dangerous and unchosen (Rich, 1995). Childbirth is a moment between life and death for a woman. There is a moment when Zikora cannot bear the pain of childbirth "Then came a wave of exhaustion, a tiredness limp and bloodless. I was leaving my body. I could die. I could die here (Adichie, 2020)." Women sacrifice everything they can and they have to provide life for their children. No matter how painful the process of childbirth, women need to stay strong and to take all the risks for the life of their children.

Men can escape from their responsibilities as fathers, yet it is difficult for women to do so. Their motherhood nature is strong although it is complicated. Rich (Rich, 1995) poins out that Women do not simply give birth; she makes it possible for the child to go on living. She further mentions that to have borned and reared a child is to have done that thing which patriarchy joins with physiology to render into the 
definition of femaleness. But also, it can mean the experiencing of one's own body and emotions in a powerful way. We experience not only physical, fleshly changes but the feeling of a change in character. When Zikora first see and hold her baby, her feelings are complicated. She does not able to recognize and figure out her own feeling. "Now here he was wrapped like a tidy sausage roll and placed on my chest. He was warm and so very small. I held him with stiff hands. I was suspended in a place of no feeling, waiting to feel. I could not separate this moment from the stories of this momentyears of stories and films and books about this scene, mother and child, mother meeting child, child in mother's arms. I knew how I was supposed to feel, but I did not know how I felt. It was transcendental (Adichie, 2020)."

The feeling of being ready to become a mother does not just come. Even for women who had always known they would be a mom, or felt as if their purpose in life was to become a mother, the long-term development of becoming a mother was not immediately integrated into their identities. After bringing the baby home, some women were surprised that it took a significant amount of time to feel connected to their children (Laney et al., 2015). Even some women suffer from baby blues, a feeling of sadness or unhappy a mother may have in their first few days after childbirth. It is possibly happened because the feeling of motherhood is not natural and it indeed takes a process.

My son began to cry. He was fed, his tiny belly tautly round, and yet he cried. He cried and cried. "Some babies just cry," my mother said calmly. What am I supposed to do with him? I thought to myself. It had only been a few days. There would be more days and weeks of this, not knowing what to do with a squalling person whose needs I feared I could never know (Adichie, 2020)."

Zikora is not only confused with her feeling about the baby, but she also does not know how to handle the baby. This phase is also frustrating for her since she needs to connect herself more with the baby, so she can communicate and understand what the baby wants. There is no particular subject at school teachs women how to become a mother. It does come by instinct and is learned by doing. Rich (Rich, 1995) also mentions about this that motherhood is earned, first through an intense physical and psychic rite Of Passage' pregnancy and childbirth - then through learning to nurture, which does not come by instinct. The struggle of women in motherhood is not only exhausting physically but also mentally and emotionally. Women must exert all their body and soul to be able to look after, care for and raise children. The process they will go through in motherhood will be very long and will always be full of learning processes.

However the sacrifices that a woman makes to the institution of motherhood are invisible; we only become aware of them when they are not made, or when they are made in a way that is untranslatable to us given the specific limitations of our ideological governances (Gardner, 2016). This idea means that in patriarchal society to be a woman is to be a mother and motherhood is something all cultures encourage women to pursue. Most women in history have become mothers without choice, and an even greater number have lost their lives bringing life into the world (Rich, 1995). Most men under patriarchy exclude themselves from women's struggle in motherhood. They give all the responsibilities of child raising to women. "Ours was an ancient story, the woman wants the baby and the man doesn't want the baby and a middle ground does not exist (Adichie, 2020)." As Zikora's partner does want the baby, he runs away from his responsibilty and acts as if the baby is not a human being that he 
needs to take care of. His absence is the source of unhappiness and depression Zikora has to go through in her transition to motherhood.

"I missed Kwame. I looked ahead and saw a future dead with the weight of his absence. I thought of getting a new number and calling him, to tell him we could make it work, that he could do as little as he wanted as a father just as long as he was there. But I was wearied of his rejection, his ignoring my texts, his blocking my number, and Ifelt translucent, so fragile that one more rejection would make me come fully undone (Adichie, 2020)."

Furthermore, the transition to motherhood can also bring happiness to a woman. It can be found when they are doing mothering. Motherhood and mothering although both seem to share similar ideas but they are actually not. Adrienne Rich's distinction between motherhood and mothering, is principally organized by two standpoints: motherhood as institution and ideology, and mothering as experience and identity. The term "motherhood" refers to the patriarchal institution of motherhood, which is maledefined and controlled and is deeply oppressive to women, whereas the word "mothering" refers to women's experiences of mothering and is female-defined and centred and potentially empowering to women (Hallstein et al., 2020).

"My son. Those words: my son. He was my son. He was mine. I had given

birth to him and I was responsible for him and already he knew me, moving his face blindly at my breasts. He was mine, and his tiny translucent arms lay precious against my skin. He was mine. My son. I would die for him. I thought this with a new wonder because I knew it to be true; something that had never been true in my life now suddenly was true. I would die for him. His tiny tongue quivered as he cried his highpitched, screeching cry. My mother took him from me and paced back and forth, holding him pressed to her chest, and soon he fell asleep (Adichie, 2020)."

Through mothering women can build and find another side of themselves. Becoming a mother causes women to modify several areas of their identities. Then the process of becoming a mother is one of negotiation between a woman's identity as an autonomous individual and a woman's identity in relationship as a mother (Laney et al., 2015). To become a mother, women cannot be selfish and become an egoist. There is somebody else that they must take care of, that will depend his/her life to them. Although Zikora's transition to motherhood is challenging, but when she looks at her son she finds herself as like somebody else. She who first finds it difficult to connect with the baby, through her process of mothering ends up with will do anything for him and ready to sacrifice everything from him. This kind of feeling empowers women to be stronger. If the transition to motherhood makes them weak, self-loss, but the mothering process emerges love and happiness. In both motherhood and mothering process, women always need to communicate with their ownselves. They must be able to modify feeling and emotion based on the challenges they are facing with. Both physical and mental strenght, also self-control must be owned by women who are about to face transition to motherhood, motherhood, and as well as mothering process. They cannot depend on men since men are often excluded themselves from parenthood as they believe that childcare are the responsibility of women.

\section{CONCLUSION}

Zikora's pregnancy is unexpected. Her partner does not want the baby and decides to abondon her. This fact becomes the cause of all the sadness and depression in Zikora's transition to motherhood. She spents most of her time crying and persuate 
him to come back. Men's absence contribute a lot to women's suffering in motherhood. As the process of motherhood is intense and hard, women need a support system to give them strenght. Zikora also experiences ups and downs in her pregnancy. Women have to fight with physical changes and psychological pressures during their pregnancy. The difficult time does not end up there. The pain of childbirth is real. Zikora experiences how dangerous a childbirth for a woman is. The sacrifices that a woman makes to the institution of motherhood are invisible. Most of them have to struggle themselves. They must be able to modify feeling and emotion based on the challenges they are facing with. Both physical and mental strenght, also self-control must be owned by women who are about to face transition to motherhood, motherhood, and as well as mothering process.

\section{REFERENCES}

Adichie, C. N. (2020). Zikora (1st ed.). Seattle: Amazon Original Stories.

Alazaz, H. (2016). Divergent perspectives : The representation of the maternal subject in American postwar novels about the rejection of motherhood. International Journal of English and Literature, 7(March), 27-34. https://doi.org/10.5897/IJEL2015.0795

Carlshamre, K. (2017). Living the Paradox: The Transition to Motherhood in Two European Novels, the French A Happy Event and the Swedish Bitter Bitch. Women's Studies, 46(2), 113-131. https://doi.org/10.1080/00497878.2017.1264225

Gardner, R. L. (2016). Subverting Patriarchy with Vulnerability: Dismantling the Motherhood Mandate in Toni Morrison's Beloved. Women's Studies, 45:3(June), 203-214. https://doi.org/10.1080/00497878.2016.1149029

Hallstein, L. O. B., Reilly, A. O., \& Giles, M. V. (2020). THE ROUTLEDGE COMPANION (First; L. O. B. Hallstein, A. O. Reilly, \& M. V. Giles, eds.). New York: Routledge.

Laney, E. K., Hall, M. E. L., Anderson, T. L., \& Willingham, M. M. (2015). Becoming a Mother: The Influence of Motherhood on Women's Identity Development. Identity: An International Journal of Theory and Research, 2(May 2015), 162145. https://doi.org/10.1080/15283488.2015.1023440

Meier, J. (2000). The Refusal of Motherhood in African American Women 's Theater. MELUS, 25(3/4). https://doi.org/https://doi.org/10.2307/468239

Osigwe, K. C., \& Nekede, F. P. (2021). Zikora: A Short Story, English Academy Review. A Journal of English Studies, (June), 34. https://doi.org/10.1080/10131752.2021.1926106

Rich, A. (1995). Of Woman Born: Motherhood as Experience and Institution (Second Edi; A. Rich, ed.). United States of America: W.W. Norton \& Company, Inc.

Tanjim, T. (2016). Portrayal of Motherhood by Female Authors in American Literature in the Light of The Awakening, Herland and The Narrow House. Retrieved from http://dspace.bracu.ac.bd/xmlui/bitstream/handle/10361/7669/13203026_ENH. pdf? sequence $=1 \&$ is Allowed $=\mathrm{y}$ 